Revista Complutense de Educación

ISSNe: 1988-2793

http://dx.doi.org/10.5209/RCED.60867

\title{
Educación no formal y empleabilidad de la juventud.
}

Autor: Miguel Angel Santos Rego, Mar Lorenzo Moledo y Ana VázquezRodríguez.

Editorial: Síntesis

Año de publicación: 2018

$N^{o}$ de Páginas: 160

ISBN: 978-84-9171-094-3

La presente obra se articula a partir de la tesis que sostiene que los programas de educación y/o aprendizaje no formal potenciarán de modo significativo competencias, destrezas y valores susceptibles de elevar los niveles e indicadores de empleabilidad de los jóvenes, contribuyendo a la mejora de su inclusión en corrientes de participación comunitaria y de su capital social y cultural. En este sentido, el libro trata de ofrecer una visión alternativa a los paradigmas que entienden los procesos educativos desde una perspectiva lineal, para dar un salto cualitativo hacia un nuevo modelo, acorde a la complejidad de las actuales sociedades de la información o del conocimiento, que reconozca la multiplicidad de factores y circunstancias que afectan al aprendizaje humano, así como a su complejidad evolutiva en el plano individual, social e interaccional.

Para ello, la obra se desarrolla en seis capítulos que pretenden mostrar la importancia de considerar los procesos educativos no formales en la empleabilidad de la juventud de las sociedades contemporáneas.

En el primer capítulo, titulado "La educación no formal: concepto y aspectos definitorios", se realiza una aproximación al concepto de educación no formal, así como una configuración y clasificación de la misma. Todo ello, desde una perspectiva pedagógica orientada hacia el desarrollo personal y cultural de la ciudadanía, así como hacia la promoción de la equidad en la educación.

En el segundo capítulo, titulado "Juventud y educación no formal en el marco europeo", se comienza por abordar el desempleo juvenil como una de las principales problemáticas de la juventud contemporánea. A continuación, se definen las políticas de juventud que desarrolla la Unión Europea, incidiendo en la relación educación-empleo. Y finalmente, se explica el impulso de la educación no formal como acción transversal en las políticas de juventud dentro del marco europeo. De este capítulo, cabe destacar que la obra aporta un interesante enfoque que articula un constructo de la juventud que sitúa en el eje central las significaciones asociadas a la configuración social de cada país, así como las transiciones entre la infancia y la edad adulta.

En el tercer capítulo, titulado "La educación no formal en el contexto español", se exponen los comienzos y la proyección de la educación no formal en España, algunas claves de las políticas de juventud españolas, así como el balance y perspectivas de la participación social de la juventud en España. En este sentido, los autores alertan sobre las bajas tasas de participación juvenil y señalan la importancia de 
desarrollar nuevos enfoques que orienten el compromiso comunitario e impulsen la participación social y política de la juventud.

En el cuarto capítulo, titulado "La validación y el reconocimiento del aprendizaje no formal", se aborda dicha temática desde una perspectiva española y desde una perspectiva europea, señalando las primeras aproximaciones a la validación, su conversión en una de las prioridades de la agenda europea y las perspectivas de futuro.

El quinto capítulo, titulado "Juventud y competencias para el mercado laboral" se divide en dos partes. En la primera, se discute el vínculo entre educación y trabajo, incidiendo en las demandas del mercado laboral hacia la juventud a partir de las principales evidencias obtenidas en la investigación sobre educación y empleo. Y en la segunda, se aborda la importancia de la participación en acciones de educación no formal en el desarrollo de las competencias demandadas en la juventud desde el ámbito laboral.

Finalmente, en el sexto capítulo, titulado "El desarrollo de competencias a través de la educación no formal", se comienza por exponer tres programas de educación no formal para la juventud: Galaeuropa, Iniciativa Xove y Voluntariado Xuvenil, que surgen como respuesta a la movilidad actual de la juventud, a la necesidad de desarrollar un nuevo modelo de participación juvenil, y a la necesidad de fomentar las actitudes cívicas y sociales de los jóvenes. A continuación, se realiza un análisis de las aptitudes interpersonales y competencias que desarrollan los jóvenes que participan en dichos programas de educación no formal. Y finalmente, se realiza un análisis de las aptitudes interpersonales y competencias demandadas desde el mercado laboral, estudiando el valor que los empleadores les conceden y comprobando si la participación de los jóvenes en programas de educación no formal abre otras vías y opciones que permitan mejorar su empleabilidad.

La situación socioeducativa y laboral de la juventud representa uno de los mayores retos a los que se enfrentan las sociedades contemporáneas. $\mathrm{Y}$ en este sentido, la presente obra aporta una serie de análisis capaces de abrir una nueva mirada a profesionales e investigadores del ámbito educativo acerca de la reciente, aunque ya consolidada, relación entre el mundo educativo y laboral. Todo ello, con el objetivo de generar nuevas oportunidades, a partir de la superación de los modelos educativos de tipo lineal, que permitan a la juventud de hoy ser parte activa de las actuales sociedades marcadas por la conectividad y la movilidad.

María Naranjo Crespo

Universidad Complutense de Madrid marnaran@ucm.es 